\title{
ANÁLISE DA VIABILIDADE DO USO DE BIODIGESTORES EM PROPRIEDADES RURAIS $^{1}$
}

\author{
Renan Souza Moura ${ }^{2}$ \\ Ricardo Carrasco Carpio ${ }^{3}$ \\ Corina Fonseca de Carvalho Macedo ${ }^{4}$ \\ Deborah Silva Pinheiro 5 \\ Larissa Soares Figueiredo ${ }^{6}$ \\ Letivan Cambraia Freire Junior ${ }^{7}$
}

\begin{abstract}
RESUMO
A agropecuária está em constante crescimento e a intensificação em seus sistemas de produção tem como consequência o aumento das agressões ambientais, decorrente, muitas vezes, dos dejetos de animais, gerando graves problemas. Assim, a estabilização desses dejetos em biodigestores tem merecido destaque, em função dos aspectos sanitários e também como potenciais na geração de energia renovável. Biodigestores são compartimentos fechados, onde toda biomassa contida em seu interior sofre o processo de fermentação, por meio da atividade de bactérias anaeróbicas. Por meio deste processo de biodigestão anaeróbia, os dejetos são transformados em biofertilizante, liberando o biogás. Este trabalho tem como objetivode dimensionar e projetar o desenvolvimento de um biodigestor como fonte de geração de energia para a fazenda da Chácara, situada no município de Campo Belo- MG, bem como análise de sua viabilidade econômica.
\end{abstract}

Palavras-chave: Biodigestor. Biogás. Viabilidade econômica.

${ }^{1}$ Como citar este artigo: MOURA, Renan Souza et al. Análise da viabilidade do uso de biodigestores em propriedades rurais. ForScience: revista científica do IFMG, Formiga, v. 5 , n. 3 , jul./dez. 2017.

${ }^{2}$ Doutor em Engenharia Elétrica pela Universidade Federal de Itajubá (Unifei). Atualmente é professor do Instituto Federal Minas Gerais (IFMG) - Campus Formiga. Currículo Lattes: http://lattes.cnpq.br/6981517353494441. E-mail: renan.moura@ifmg.edu.br.

${ }^{3}$ Doutor em Engenharia Mecânica pela Unifei. Atualmente é professor do IFMG - Campus Arcos. (http://lattes.cnpq.br/9223225565564084). E-mail: ricardo.carpio@ifmg.edu.br.

${ }^{4}$ Alunodo curso de Engenharia Elétrica do IFMG - Campus Formiga. E-mail: corinafcm@hotmail.com. Currículo Lattes: http://lattes.cnpq.br/3769879056045115.

${ }^{5}$ Aluno do curso de Engenharia Elétrica IFMG - Campus Formiga. Currículo Lattes: http://lattes.cnpq.br/8568976506794970. E-mail: deborahpinheiro33@yahoo.com.br.

${ }^{6}$ Aluno do curso de Engenharia Elétrica do IFMG - Campus Formiga. Email: larissasoares21@outlook.com. Currículo Lattes: http://lattes.cnpq.br/1412266596357999.

${ }^{7}$ Bacharel em Engenharia Elétrica pelo IFMG - Campus Formiga. Atualmente é proprietário da Empresa Kz Engenharia e Energia. Email: letivanjr@gmail.com. Currículo Lattes: http://lattes.cnpq.br/9668623706878073. 


\section{INTRODUÇÃO}

A sociedade está cada vez mais dependente da energia elétrica, tendo em vista que quase todas as atividades humanas são movidas por algum equipamento que necessita desta energia, seja nas indústrias, comércio, meios de comunicação, de transporte, de lazer, entre outros (MOREAU, 2013). Porém, essa energia, muitas vezes, é advinda de combustíveis fósseis, e, em alguns casos de usinas termelétricas, sendo prejudicial para o meio ambiente, além de apresentar um alto custo.

Hoje, com a ideia de um mundo sustentável, a humanidade vem procurando um meio de produzir energia elétrica de uma forma que não prejudique o meio ambiente, assim, destacam-se as energias renováveis (OLIVEIRA, 2014). O Brasil apresenta bastante recurso para investir em energias renováveis, porém faltam ainda incentivos governamentais. De acordo com a conferência COP21, o Brasil tem como meta alcançar, até 2030, 33\% de energia elétrica proveniente de fontes renováveis, como eólica, solar, biomassa, entre outras, desconsiderando as hidrelétricas, que, embora produzam energia a partir de um recurso natural, causam grande impacto ambiental em sua construção (VIEIRA, 2015).

Dentre as energias renováveis existentes, a proveniente da biomassa é de grande importância para a preservação do meio ambiente, pois os resíduos gerados pelas indústrias e os dejetos de animais, por exemplo, quando tratados de forma inadequada contaminam o solo, as águas e contribuem, também, para o aquecimento global. Ao serem lançados no meio ambiente, estes efluentes liberam o gás metano na atmosfera, que é 21 vezes mais poluente que o gás carbônico, no que se refere ao efeito estufa (OLIVEIRA, 2009).

$\mathrm{O}$ processo de digestão anaeróbica, em biodigestores, torna-se uma opção bem atraente para o tratamento dos resíduos, visto que, com a degradação destes dejetos, ocorre a produção do biogás, que pode ser utilizado como uma fonte para produção de energia elétrica. É importante ressaltar que este processo ainda produz o biofertilizante, que apresenta um alto teor de nutrientes necessários para as lavouras (OLIVEIRA, 2012).

O foco deste trabalho é demonstrar como o biogás pode ser utilizado como fonte energética através da construção de biodigestores, que utilizam a digestão anaeróbica de dejetos oriundos da atividade pecuária. Nas próximas seções, todos os procedimentos para a construção do biodigestor serão demonstrados assim como o custo envolvido.

\section{REFERENCIAL TEÓRICO}

ForSci.: r. cient. IFMG, Formiga, v. 5, n. 3, e00282, jul./dez. 2017. 


\subsection{Biodigestores}

O biodigestor é constituído por um compartimento fechado onde ocorre a digestão anaeróbica de toda a biomassa contida em seu interior. Para que esta digestão seja efetuada com sucesso não pode haver a existência de ar. Como subproduto dessa fermentação tem-se o biogás, que produz energia, e o biofertilizante (ECYCLE, 2017). Normalmente os biodigestores são construídos no subsolo no intuito de obter uma temperatura mais elevada e constante em seu interior e assim produzir uma quantidade de biogás satisfatória (OLIVEIRA, 2009).

Existem dois tipos de biodigestores, os contínuos e os descontínuos. Os contínuos são compostos por uma caixa de carga, uma câmara de digestão e uma caixa de descarga (RIZZONI, 2012). Assim, os dejetos são inseridos na caixa de carga, continuamente, que passa para a câmara, onde acontecerá a fermentação. Por fim, o biofertilizante formado sai pela caixa de descarga, ou seja, nesse processo não é preciso abrir o biodigestor para a retirada do subproduto, e a entrada de dejetos pode ocorrer diariamente, além disso, estes biodigestores produzem o biogás continuamente. Dentre os biodigestores contínuos os mais comuns são o indiano, o chinês e o canadense - este último conhecido também como fluxo tubular - que serão citados posteriormente. Por outro lado, os biodigestores descontínuos somente serão abertos para a renovação dos desejos após a produção do biogás e do biofertilizante, dependendo do material que foi inserido, esta atividade pode demorar 90 dias (BARROS, [s. d.]).

Os materiais utilizados como carga para qualquer um desses biodigestores têm que ser diluídos em água, e a quantidade desta dependem do tipo de dejeto (LUCAS JÚNIOR, [s. d.]).

\subsection{Biogás}

O biogás é composto principalmente de metano (50\% a 80\% em volume) e dióxido de carbono (20\% a $40 \%$ em volume), além de uma pequena porcentagem de hidrogênio $\left(\mathrm{H}_{2}\right)$, nitrogênio $\left(\mathrm{N}_{2}\right)$ e gás sulfídrico $\left(\mathrm{H}_{2} \mathrm{~S}\right)$. Percebe-se que, o metano é o componente que se apresenta em maior concentração no biogás. Este gás é considerado inodoro, incolor e altamente combustível (JUNQUEIRA, 2014). Devido a este fato, o biogás se torna uma alternativa energética, com um poder calorífico entre 5.000 a $7.000 \mathrm{Kcal}$ por metro cúbico, 
podendo chegar até mesmo a $12.000 \mathrm{Kcal}$ por metro cúbico, quandosubmetido a uma purificação (GASPAR, 2003).

A utilização da energia produzida pelo biogás pode ser aproveitada para geração de energia elétrica e térmica, iluminação, combustível para veículos, aquecimento, entre outras utilidades. Normalmente, as fazendas que possuem biodigestores utilizam o biogás para a produção de energia elétricacom a finalidade de economizar.

\subsection{Biofertilizante}

A digestão anaeróbica, além de produzir o biogás, resulta, também, na produção do biofertilizante. Este subproduto é uma excelente opção de adubo para as plantas, pois além apresentar um baixo custo comparado aos fertilizantes químicos, apresenta em sua composição nutrientes necessários para o desenvolvimento das lavouras e não causa danos ao meio ambiente (OLIVER et al, 2008). Além disto, é um material orgânico, isento de agentes causadores de doenças e pragas às plantas.

\section{METODOLOGIA}

Primeiramente, foi necessária a escolha do tipo de biodigestor mais viável para o local. No caso da fazenda da Chácara foiescolhido o biodigestor indiano, pois é um biodigestor contínuo, seguro e apresenta poucas chances de escapamento do biogás. A fazenda dispunhade um rebanho bovino com 50 vacas leiteiras e 50 bois de corte. Cada animal deste eliminava uma quantidade mínima de dejetos, ou seja, fezes e urina, por dia. A vaca leiteira por ser mais pesada eliminava aproximadamente $25 \mathrm{~kg}$ de dejetos por dia, já o boi de corte eliminava $15 \mathrm{~kg}$.Portanto, a fazenda apresentava uma quantidade de $2000 \mathrm{~kg}$ de dejetos por dia, já que dispõe de um rebanho bovino com 50 vacas leiteiras e 50 bois de corte.

Após saber a quantidade de esterco que era produzido diariamente na fazenda, importava saber a quantidade de água necessária para diluir estes dejetos, visto que, para que ocorra a produção de biogás corretamente, o biodigestor deve ser alimentado com dejetos diluídos em água.No caso de esterco bovino, para cada parte de dejeto tem uma parte de água, ou seja, 1:1. Assim, de acordo com os dados da fazenda, para $2000 \mathrm{~kg}$ de dejetos bovinos seriam necessários 2000 litros de água. 
Com essas informações obtidas foi possível calcular o volume do biodigestor. A carga diária que será armazenada no biodigestor é a soma da quantidade de dejetos com a quantidade de água, como mostra a Equação 1.

$$
\text { cargadi á ria }=\text { dejetos }+ \text { á gua }
$$

cargadi á ria $=2000+2000=4000 l$

Com o valor da carga diária, calculou-se o volume útil do biodigestor, dado pela seguinte Equação 2:

$$
V \dot{u} \text { til }=\frac{\text { cargadiá riaxtempodereten } c ̧ \tilde{a} o}{1000}
$$

Como os dejetos para a alimentação do biodigestor desta fazenda eram de bovinos, o tempo de retenção costuma ser de 30 dias, assim:

$V$ útil $=\frac{4000 \times 30}{1000}=120 \mathrm{~m}^{3}$

Com o volume útil, foi possível calcular o volume bruto do biodigestor. Considerandose que o volume bruto é $10 \%$ a mais do volume útil, como está representado na Equação 3.

$$
\text { Vbruto }=\text { V́ tilx } 1,10=120 \times 1,10=132 \mathrm{~m}^{3}
$$

Sabendo o volume total do biodigestor, calculou-se a altura do biodigestor e seu diâmetro interno.

Existe uma faixa aceitável para a relação Di/H (diâmetro/altura) do biodigestor, como mostra a Equação 4. 


$$
0,6 \leq \frac{D i}{H} \leq 1
$$

Como no caso da fazenda da Chácara o volume bruto do biodigestor foi de $132 \mathrm{~m}^{3}$, esta razão deve ser mais próxima de 1, proporcionando uma maior eficiência de fermentação (DO BÚ ARAÚJO et al, 2015). Sabendo esta relação, supõe-se um valor para a altura ou para o diâmetro do biodigestor, desde que este valor atenda a relação da Equação 4. Supôs-se que o diâmetro do biodigestor fosse 5,5 m, assim, calculou-se a altura pela Equação 5 .

$$
\text { Vbruto }=\frac{\pi x D i^{2} x H}{4}
$$

$H=\frac{4 \times 132}{\pi \times 30,25}=5,56 \mathrm{~m}$

Uma vez que a razão Di/H corresponde a 0,99 ,os valores da altura e do diâmetro do biodigestor estão dentro do permitido.

A altura encontrada é denominada de altura útil. No entanto, foi preciso calcular, também, a altura total do biodigestor. Para isso, basta adicionar na altura útil $0,15 \mathrm{~m}$, correspondente ao desnível devido à pressão do biogás, e mais $0,1 \mathrm{~m}$, como taxa de segurança, evitando, assim, transbordamento (DO BÚ ARAÚJO et al, 2015). Dessa forma, ao todo se adicionam $0,25 \mathrm{~m}$ ao valor da altura útil, o que no caso correspondeu àum valor de altura total de 5,81 m.

Depois de definido as dimensões do biodigestor, calcularam-se as dimensões do gasômetro.Para calcular as dimensões do gasômetro, é necessário saber quantos metros cúbicos de biogás são produzidos por dia.No caso de estercos bovinos, $25 \mathrm{~kg}$ de dejetos produzem $1 \mathrm{~m}^{3}$ de biogás, assim, como na fazenda a quantidade de dejetos eliminados por dia era de aproximadamente $2000 \mathrm{~kg}$, então, tinha-se uma produção de $80 \mathrm{~m}^{3}$ de biogás diária. Com esses dados, foi possível calcular o volume do gasômetro, conforme indicado pela Equação 6. 


$$
V g=\frac{\text { volumedebiog á } s / \text { dia }}{2}=40 \mathrm{~m}^{3}
$$

O diâmetro do gasômetro está relacionado com o diâmetro do biodigestor, que pode ser calculado por meio da Equação 7.

$$
D g=D i+0,1
$$

$D g=5,5+0,1=5,6 m$

Com o valor do diâmetro, calcula-se a altura útil do gasômetro, que também está relacionada com o seu volume, como mostra a Equação 8.

$$
H g u ́ t i l=\frac{4 x V g}{\pi x D g^{2}}
$$

$H g$ útil $=\frac{4 \times 40}{\pi \times 5,6^{2}}=1,62 \mathrm{~m}$

Assim, sabendo a altura útil do gasômetro, calcula-se sua altura total. Como no cálculo da altura total do biodigestor, para se calcular a altura total do gasômetro, considera-se o desnível provocado pela pressão e uma taxa de segurança, ambos com os mesmos valores anteriores, conforme apresentadopela Equação 9.

$$
\text { Hgtotal }=H g \text { útil }+P+\text { Taxadesegurança }
$$

Hgtotal $=1,62+0,15+0,1=1,87 m$

Para facilitar a condução dos dejetos até a câmara de fermentação e a caixa de saída, os tubos de carga e descarga do biodigestor devem apresentar uma inclinação. Segundo (LUCAS JÚNIOR, [s. d.]) esta inclinação deve ser em torno de $30^{\circ}$. A altura destes tubos até ForSci.: r. cient. IFMG, Formiga, v. 5, n. 3, e00282, jul./dez. 2017. 
o fundo desta câmara costuma ser $30 \mathrm{~cm}$, a fim de impedir que as impurezas mais pesadas afetem na condução dos dejetos, como mostra a Figura 1 (LUCAS JÚNIOR, [s. d.]).

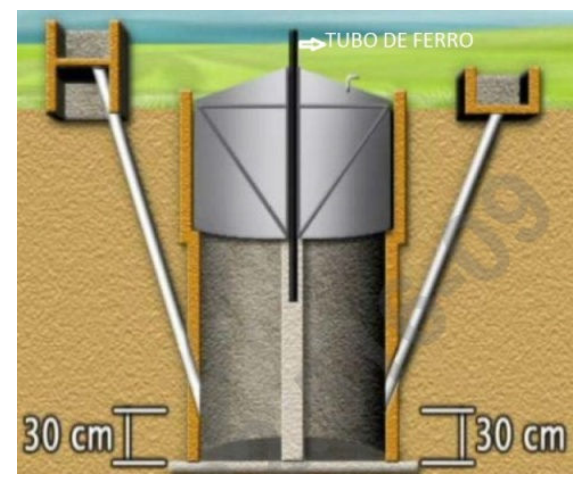

Figura Erro! Nenhuma sequência foi especificada.- Biodigestor do tipo indiano

Após saber a inclinação desses tubos, dimensionam-se seus comprimentos. Para melhor entendimento de como dimensionar o cano de descarga, observa-se a Figura 1. Como se pode perceber, a altura total do biodigestor menos a altura do tubo de carga com o fundo da câmara de biodigestão, a inclinação do tubo de descarga e o afastamento do cano de descarga do biodigestor - que costuma ser 1,6 m-formam um triângulo retângulo. Portanto, fica fácil calcular o comprimento do tubo de descarga, como se pode visualizar na Equação 10.

$$
\text { canodedescarga }=\sqrt{(\text { Hbiod } .-0,3)^{2}+\text { afast }^{2}}
$$

canodedescarga $=\sqrt{(5,81-0,3)^{2}+1,6^{2}}=5,74 \mathrm{~m}$

O tubo de carga tem praticamente o mesmo comprimento, porém como a caixa de carga está0,6 m acima do solo soma-se esse valor em seu comprimento.Assim, obteve-se um comprimento do cano de carga equivalente a $6,34 \mathrm{~m}$.

Observa-se, também, na Figura 1, um tubo de ferro, chamado de tudo guia, cuja dimensão costuma ser calculada em torno de $10 \%$ a mais que a altura total do gasômetro. Como a altura total do gasômetro dimensionado para a fazenda era 1,87 m, o tubo guia tinha, portanto, uma altura de $2,06 \mathrm{~m}$.

Por fim, dimensiona-se a caixa de carga e descarga do biodigestor. Como a finalidade dessas caixas é armazenar a biomassa antes e depois da fermentação, seus volumes, portanto, dependerão da razão entre o volume de dejetos que forem inseridos diariamente no ForSci.: r. cient. IFMG, Formiga, v. 5, n. 3, e00282, jul./dez. 2017. 
biodigestor e o tempo de retenção. Essa razão é multiplicada por 1,15, como margem de segurança, caso a quantidade de dejetos obtidos em um dia ultrapasse o previsto. Assim, obtém-se, por meio da Equação 11, o volume das caixas.

$$
\text { Vol } \text {.dascaixas }=\frac{\text { Vbruto }}{\text { Tempodereten } c ̧ a \tilde{o}} \times 1,15
$$

Vol . dascaixas $=\frac{132}{30} \times 1,15=5,06 \mathrm{~m}^{3}$

A altura total recomendável da caixa de carga é $1,20 \mathrm{~m}$, sendo que a mesma deve ser construída $0,6 \mathrm{~m}$ acima do solo. Assim, os $0,6 \mathrm{~m}$ restantes são a altura interna da caixa. A caixa de descarga apresenta também os mesmos $0,6 \mathrm{~m}$ de altura interna, porém é construída no mesmo nível do solo (LUCAS JÚNIOR, [s. d.]).

As medidas da largura e do comprimento das caixas são dadas pela Equação 12.

$$
\text { medidadoslados }=\sqrt{\frac{\text { volumedacaixa }}{\text { alturadacaixa }}}
$$

medidadoslados $=\sqrt{\frac{5,06}{0,6}}=2,9 \mathrm{~m}$

Então, cada caixa apresentou 0,6 $\mathrm{m}$ de altura interna, 5,06 $\mathrm{m}^{3}$ de volume e 2,9 $\mathrm{m}$ de comprimento e largura.

Com todos esses valores do dimensionamento encontrados, obteve-se o projeto de um biodigestor do tipo indiano, que poderia ser construído na fazenda da Chácara.

\section{RESULTADOS E DISCUSSÕES}


MOURA, R. S. et al. Análise da viabilidade do uso de biodigestores em propriedades rurais

O objetivo principal deste capítulo é analisar a viabilidade econômica do projeto do biodigestor na fazenda da Chácara. Para isso, são realizados cálculos do fluxo de caixa, payback, valor presente líquido e da taxa interna de retorno.Porém, primeiramente, será analisadaa relação entre a quantidade de biogás produzido no biodigestor e o custo de investimento para a construção do mesmo.

Como já foi mencionado na metodologia, a fazenda produzia $80 \mathrm{~m}^{3}$ de biogás diariamente. Com isto, é possível obter a quantidade de energia elétrica produzida, por meio da Equação 13.

$$
\text { Energiael é trica }=P C \square E \square \eta
$$

Onde:

$$
\begin{aligned}
& \text { PC: Poder calorífico do biogás em } \mathrm{kWh} / \mathrm{m}^{3} \text {; } \\
& \text { E: Quantidade de biogás } \mathrm{em} \mathrm{m}^{3} \text {; } \\
& \eta \text { : Rendimento do conjunto motor-gerador. }
\end{aligned}
$$

$$
\text { Energiael é trica }=6,5 \square 80 \square 0,25=130 \mathrm{kWh}
$$

Assim, em um mês a quantidade de energia gerada é de aproximadamente $3.900 \mathrm{kWh}$. Para que ocorra essa geração de energia elétrica a partir do biogás, foi utilizado um grupo motor-gerador com alternador WEG no modelo GTA162AI30 de 37,5 kVA. Este gerador é alimentado com o biogás produzido no biodigestor projetado para a fazenda da Chácara.

Após a realização do projeto e da escolha do conjunto motor-gerador, foi feita uma análise do investimento inicial da construção do biodigestor na fazenda, como pode ser observado na Tabela 1.

Tabela 1 - Gastos para a construção do biodigestor.

\begin{tabular}{cc}
\hline Despesas & Valor \\
\hline Construção & $\mathrm{R} \$ 14.663,88$ \\
Gerador & $\mathrm{R} \$ 50.000,00$ \\
Projeto e Instalação & $\mathrm{R} \$ 5.000,00$ \\
Total & $\mathrm{R} \$ 69.663,88$ \\
\hline
\end{tabular}

Fonte: Próprio autor.

ForSci.: r. cient. IFMG, Formiga, v. 5, n. 3, e00282, jul./dez. 2017. 
MOURA, R. S. et al. Análise da viabilidade do uso de biodigestores em propriedades rurais

Como pode perceber na Tabela 1, os gastos iniciais com o biodigestor ficaram, aproximadamente, R $\$ 70.000,00$. Porém, o grupo gerador requer constante manutenção para o seu funcionamento. As manutenções representam, de modo geral, 4\% do valor do investimento total realizado para construir e operar o biodigestor (ADVFN, 2017). Esse valor será corrigido, a partir do segundo ano de funcionamento, com a inflação média de 6,93\% obtida nos últimos anos, segundo o IPCA (Índice de Preços ao Consumidor Amplo) que é o índice oficial do Governo Federal para obter os índices de inflação.

A Tabela 2 mostra a economia gerada pela utilização do biodigestor na fazenda da Chácara no período de 10 anos. Foi considerada, também, a inflação média de 6,93\% ao ano para os valores de tarifa de energia.

Tabela 2 - Economia gerada com a utilização do biodigestor.

\begin{tabular}{|c|c|c|c|c|c|}
\hline Período (Ano) & $\begin{array}{c}\text { Geração } \\
\text { (kWh/ano) }\end{array}$ & $\begin{array}{c}\text { Tarifa } \\
(\mathbf{R} \$ / \mathbf{k W h})\end{array}$ & Custo & $\begin{array}{c}\text { Remuneração } \\
\text { Energia }\end{array}$ & Fluxo de Caixa \\
\hline 0 & 0 & $\mathrm{R} \$ 0,00$ & $\begin{array}{r}-\mathrm{R} \$ \\
69.663,88\end{array}$ & $\mathrm{R} \$ 0,00$ & -R\$ 69.663,88 \\
\hline 1 & 46800 & $\mathrm{R} \$ 0,48$ & $\begin{array}{c}-\mathrm{R} \$ \\
2.786,56\end{array}$ & $\mathrm{R} \$ 22.464,00$ & $-\mathrm{R} \$ 49.986,44$ \\
\hline 2 & 46800 & $\mathrm{R} \$ 0,51$ & $\begin{array}{c}-\mathrm{R} \$ \\
2.978,83\end{array}$ & $\mathrm{R} \$ 24.014,02$ & $-\mathrm{R} \$ 28.951,25$ \\
\hline 3 & 46800 & $\mathrm{R} \$ 0,55$ & $\begin{array}{c}-\mathrm{R} \$ \\
3.184,37\end{array}$ & $\mathrm{R} \$ 25.670,98$ & $-\mathrm{R} \$ 6.464,63$ \\
\hline 4 & 46800 & $\mathrm{R} \$ 0,59$ & $\begin{array}{c}-\mathrm{R} \$ \\
3.404,09\end{array}$ & $\mathrm{R} \$ 27.442,28$ & $\mathrm{R} \$ 17.573,56$ \\
\hline 5 & 46800 & $\mathrm{R} \$ 0,63$ & $\begin{array}{c}-\mathrm{R} \$ \\
3.638,97\end{array}$ & $\mathrm{R} \$ 29.335,80$ & $\mathrm{R} \$ 43.270,39$ \\
\hline 6 & 46800 & $\mathrm{R} \$ 0,67$ & $\begin{array}{c}-\mathrm{R} \$ \\
3.890,06\end{array}$ & $\mathrm{R} \$ 31.359,97$ & $\mathrm{R} \$ 70.740,30$ \\
\hline 7 & 46800 & $\mathrm{R} \$ 0,72$ & $\begin{array}{c}-\mathrm{R} \$ \\
4.158,47\end{array}$ & $\mathrm{R} \$ 33.523,81$ & $\mathrm{R} \$ 100.105,63$ \\
\hline 8 & 46800 & $\mathrm{R} \$ 0,77$ & $\begin{array}{c}-\mathrm{R} \$ \\
4.445,41\end{array}$ & $\mathrm{R} \$ 35.836,95$ & $\mathrm{R} \$ 131.497,18$ \\
\hline 9 & 46800 & $\mathrm{R} \$ 0,82$ & $\begin{array}{c}-\mathrm{R} \$ \\
4.752,14\end{array}$ & $\mathrm{R} \$ 38.309,70$ & $\mathrm{R} \$ 165.054,73$ \\
\hline 10 & 46800 & $\mathrm{R} \$ 0,88$ & $\begin{array}{c}-\mathrm{R} \$ \\
5.080,04\end{array}$ & $\mathrm{R} \$ 40.953,07$ & $\mathrm{R} \$ 200.927,76$ \\
\hline
\end{tabular}


Percebe-se na Tabela 2, que foi considerada uma geração de energia anualmente, equivalente a $46800 \mathrm{kWh}$, visto que, por mês, o biodigestor tem uma geração de $3900 \mathrm{kWh}$.

Vale ressaltar que o tempo de duração do biodigestor pode ser mais que dez anos, portanto o sistema continuará gerando economia, tornando cada vez mais atrativo este investimento.

\subsection{Payback}

Também conhecido como tempo de retorno de investimento, o paybacksignifica o tempo necessário para que o fluxo de caixa acumulado atinja um valor positivo. Apresenta uma boa estimativa da atratividade do investimento, todavia, possui algumas limitações por não levar em consideração reajustes monetários e os riscos envolvidos no investimento. Logicamente, quanto mais rápido for o payback mais atrativo será o investimento.

Para o investimento realizado na construção e operação do biodigestor, percebe-se facilmente, a partir da Tabela 2 que o tempo de retorno de investimento foi de aproximadamente 4 anos. Com a ajuda do software Excel foi possível obter o tempo exato do payback, que foi de 4 anos e 3 meses.

\subsection{Valor presente líquido (VPL)}

O VPL é outro importante método para análise de investimento. Ele é calculado a partir da diferença entre os custos e remunerações oriundas do projeto. Neste método, os valores do fluxo de caixa são corrigidos para o valor presente, a partir do desconto de uma determinada taxa de juros (NAKABAYASHI, 2015).

Para o cálculo do VPL, é utilizada a seguinte Equação:

$$
V P L=\sum_{t=0}^{n} \frac{F c n}{(1+i)^{n}}-I_{0}
$$

Onde:

$\mathrm{F}_{\mathrm{cn}}$ : Fluxo de caixa do projeto no período t;

“i”: Taxa de desconto;

$\mathrm{I}_{0}$ : Investimento inicial.

ForSci.: r. cient. IFMG, Formiga, v. 5, n. 3, e00282, jul./dez. 2017. 
Para análise do VPL considera-se que, quando o valor de VPL for negativo, significa que o investimento não é interessante, do contrário o investimento é atrativo (NAKABAYASHI, 2015).

A taxa de desconto utilizada será a Taxa do Sistema Especial de Liquidação e Custódia (SELIC), descontada do valor da taxa de inflação, por se tratar do melhor valor a ser utilizado segundo Nakabayashi (2015). O valor atual da taxa SELIC é de 11,15\% e a inflação adotada será a mesma utilizada nos cálculos acima, de 6,93\% (BANCO CENTRAL DO BRASIL, 2017). Portanto, a taxa de desconto para o cálculo do VPL será de 4,22\%.

A partir das considerações acima e novamente com o auxílio da ferramenta Excel, foi possível calcular o valor do VPL para esse investimento, igual a R \$ 5.630,74. Percebe-se que o valor é positivo, portanto o investimento mostra-se atrativo.

\subsubsection{Taxa interna de retorno (TIR)}

A TIR é o método mais utilizado para análise de investimentos. Esta técnica calcula qual a taxa de retorno do investimento, considerando os fluxos de caixa do projeto. Com esta taxa é possível comparar o retorno de um projeto com outros tipos de investimento, como poupança, por exemplo.

Apesar de muito utilizada, a TIR não é recomendada em investimentos onde ocorra mais de uma variação de sinal no fluxo de caixa. Como o projeto deste trabalho não apresenta esta característica, foi possível calcular a TIR no Excel, a partir da sua função homônima no software.

O valor calculado para este projeto foi de $24 \%$. Em comparação com a taxa SELIC, que representa a maior atratividade em investimentos conservadores, este projeto é bastante atrativo, visto que a taxa de retorno é bem maior que os $11,15 \%$ da SELIC. Vale ressaltar que dificilmente se encontra no mercado financeiro algum tipo de investimento com esta taxa de retorno.

Ao fim da elaboração deste projeto, foi informado ao proprietário da fazenda da Chácara sobre todos os custos e benefícios com a construção e operação do biodigestor. $\mathrm{O}$ mesmo se mostrou bastante interessado com o projeto, porém o que torna um pouco inviável ainda é o investimento inicial.

\section{CONCLUSÃO}

ForSci.: r. cient. IFMG, Formiga, v. 5, n. 3, e00282, jul./dez. 2017. 
Este presente trabalho relatou sobre um projeto de dimensionamento de um biodigestor na fazenda da Chácara, localizada no município de Campo Belo - MG, com o intuito de reduzir os gastos com energia elétrica proveniente das concessionárias, além de aproveitar o biofertilizante para as lavouras.

O interesse na realização deste trabalho surgiu com a preocupação no constante aumento dos custos da energia elétrica, proveniente das concessionárias, motivando, assim, o uso das energias renováveis.

A fazenda da Chácara, local onde foi projetado o biodigestor neste trabalho, apresenta uma produção suficiente de dejetos para serem utilizados no biodigestor. Outro fator importante, que também contribuiu para o interesse neste trabalho, é que este estabelecimento possui um laticínio, o qual consome muita energia, encarecendo o valor da conta de energia elétrica.

A metodologia deste trabalho descreveu todo o procedimento de como fazer um projeto de um biodigestor indiano, utilizando os dados da fazenda da Chácara. Além disso, foi explicado como que se constrói tal biodigestor e como é feita a sua operação.

Por fim, foi feita uma análise da viabilidade econômica e financeira prevendo os custos da futura instalação do biodigestor. Para esta finalidade, foram utilizados os métodos payback, VPL e o TIR. O método payback apresentou um tempo de retorno, do investimento realizado na construção do biodigestor, de 4 anos e 3 meses, sendo considerado um tempo bastante atrativo. Este projeto somente seria considerado viável se o VPL fosse positivo, e, de acordo, com os cálculos realizados o VPL atendeu este requisito. Mas, para realmente comprovar se o investimento realizado compensaria, foi necessário o cálculo do TIR. Com este índice, pôde-se perceber que este projeto é bastante atrativo, pois o valor calculado do TIR foi de $24 \%$, que é bem maior que a taxa SELIC, que representa a maior atratividade em investimentos conservadores. Vale ressaltar, então, que dificilmente se encontra no mercado financeiro algum tipo de investimento com esta taxa de retorno.

Desta forma, conclui-se que, mesmo que o investimento para a construção, implantação e manutenção do biodigestor apresente um valor alto, este projeto é um investimento bastante atrativo. 


\title{
ANALYSIS OF THE VIABILITY OF THE USE OF BIODIGESTORS IN RURAL PROPERTIES
}

\begin{abstract}
Agriculture is in constant growing and the intensification of its production systems has resulted in increased environmental aggression, often resulting from animal waste, causing serious problems. Thus, the stabilization of these wastes in biodigestors has been deserved highlights, due to the sanitary aspects and also as potential in the generation of renewable energy. Biodigestors are closed compartments, where all the biomass contained in the interior undergoes the fermentation process, through the activity of anaerobic bacteria. Through this process of anaerobic biodigestion, the waste is transformed into a biofertilizer, releasing the biogas. The objective of this work is to size and design the development of a biodigestor as a source of energy generation for the Chácara Farm, located at the city of Campo Belo, MG, as well as an analysis of its economic viability.
\end{abstract}

Keywords: Biodigestor. Biogas.Economic viability.

\section{REFERÊNCIAS}

ADVFN Brasil. Indicadores Econômicos. 2017. Disponível em:

$<$ http://br.advfn.com/indicadores/ipca $>$. Acesso em: 10 maio 2017.

BANCO CENTRAL DO BRASIL. Taxa SELIC. Disponível em: $<$ http://www.bcb.gov.br/ptbr/\#!/n/SELICTAXA >. Acesso em: 11 maio 2017.

BARROS, Talita Delgrossi. Biofertilizante. [s. d.] Disponível em:

$<$ http://www.agencia.cnptia.embrapa.br/gestor/agroenergia/arvore/CONT000fjaakw3q02wyiv 809gkz5151b3dhe.html>. Acesso em: 19 mar. 2017.

DO BÚ ARAÚJO, Maria Isabel et al. Dimensionamento de Biodigestores Indiano para a cidade de Campina Grande. Blucher Chemistry Proceedings, v. 3, n. 1, p. 1059-1068, 2015.

ECYCLE. Biodigestão de resíduos é opção para grandes quantidades de lixo orgânico. Diponível em: <http://www.ecycle.com.br/component/content/article/35-atitude/1338biodigestao-e-uma-opcao-para-o-lixo-organico-rural-e-urbano.html $>$. Acesso em: 19 mar. 2017.

GASPAR, Rita Maria Bedran Leme. Utilização de biogestores em pequenas e médias propriedades rurais, com ênfase na agregação de valor: um estudo de caso na Região de Toledo-PR. 2003. Dissertação de Mestrado, Universidade Federal de Santa Catarina. Disponível em: < https://repositorio.ufsc.br/bitstream/handle/123456789/85585/224646.pdf>. Acesso em: 10 maio 2017.

JUNQUEIRA, S. L. C. D. Geração de energia através de biogás proveniente de esterco bovino: estudo de caso na fazenda aterrado. 2014. Monografia, Universidade do Rio Janeiro, Departamento de Engenharia Mecânica DEM/POLI/UFRJ, Rio de Janeiro. Disponível em: 
$<$ http://monografias.poli.ufrj.br/monografias/monopoli10011533.pdf $>$. Acesso em: 11 maio 2017.

LUCAS JÚNIOR, Jorge de. Construção e Operação de Biodigestores. Viçosa: Universidade Online de Viçosa-UOV. [s. d.] Disponível em: <https://www.uov.com.br/cursos-onlineenergia-alternativa/construcao-e-operacao-de-biodigestores>. Acesso em: 10 fev. 2017.

MOREAU, Raul. A importância da energia nas nossas vidas e a interdependência entre a economia e a energia do país. Disponível em:

$<$ http://www.oaltotaquari.com.br/portal/2013/03/a-importancia-da-energia-nas-nossas-vidase-a-interdependencia-entre-a-economia-e-a-energia-do-pais/>. Acesso em: 11 maio 2017.

NAKABAYASHI, Rennyo. Microgeração Fotovoltaica no Brasil: viabilidade econômica. 2015. Nota Técnica, Dissertação de Mestrado, Instituto de Energia e Ambiente da USP, São Paulo. Disponível em: < http://www.abinee.org.br/informac/arquivos/mifoto.pdf $>$. Acesso em: 20 mar. 2017.

OLIVER, André de Paula Moniz et al. Manual de treinamento em biodigestão. Salvador: Winrock Internacional, 22p, 2008.

OLIVEIRA, Matias Marchesan de. Estudo da inclusão de compartimentos em biodigestores modelo canadense. 2012. Dissertação de Mestrado, Universidade Federal de Santa Maria. Disponível em: $<$ http://cascavel.cpd.ufsm.br/tede/tde_arquivos/37/TDE-201306-21T093147Z-4391/Publico/OLIVEIRA,\%20MATIAS\%20MARCHESAN\%20DE.PDF>. Acesso em: 10 maio 2017.

OLIVEIRA, Rafael Deleo. Geração de energia elétrica a partir do biogás produzido pela fermentação anaeróbia de dejetos em abatedouro e as possibilidades no mercado de carbono. 2009. Trabalho de Conclusão de Curso, Universidade de São Carlos. Disponível em: <http://www.tcc.sc.usp.br/tce/disponiveis/18/180500/tce-26042010-091847/?\&lang=br>. Acesso em: 10 maio 2017.

OLIVEIRA, Uberdam Andrade de. A importância da utilização de energias renováveis para manutenção dos recursos naturais. 2014. Disponível em: $<$ https://medium.com/meioambiente/a-importancia-da-utilizacao-de-energias-renovaveis-para-manutencao-dos-recursosnaturais-a9c1 fflac982>. Acesso em: 10 maio 2017.

RIZZONI, Leandro Becaleteet al. Biodigestão anaeróbia no tratamento de dejetos de suínos. Revista Científica Eletrônica de Medicina Veterinária, v. 9, n. 18, p. 1-20, 2012.

VIEIRA, Isabela. Dependente de hidrelétricas, Brasil quer mais energias renováveis. Disponível em: <http://agenciabrasil.ebc.com.br/geral/noticia/2015-12/dependente-dehidreletricas-brasil-quer-mais-energias-renovaveis>. Acesso em: 10 maio 2017.

Recebido em: 31/07/2017

Aprovado em: 29/08/2017

Publicado em: 13/11/2017

ForSci.: r. cient. IFMG, Formiga, v. 5, n. 3, e00282, jul./dez. 2017. 